\title{
Effects of Deferred Versus Early Umbilical Cord Clamping on Maternal and Neonatal Outcomes
}

\author{
Wafaa Taha Ibrahim Elgzar ${ }^{1}$, Heba Abdel-Fatah Ibrahim ${ }^{2, *}$, Hanan Heiba Elkhateeb ${ }^{3}$ \\ ${ }^{1}$ Obstetrics and Gynecologic Nursing, Damanhour University, Damanhour, Egypt \\ ${ }^{2}$ Obstetrics and Woman Health Nursing, Benha University, Benha, Egypt \\ ${ }^{3}$ Ostetrics and Gynaecology Medicine, General Organization of Teaching Hospitals and Institutes, Damanhour, Egypt \\ *Corresponding author: heba.abdelfattah@fnur.bu.edu.eg
}

\begin{abstract}
Background: Recent protocol proposed by the World Health Organization to manage the third stage of labour replaced the early cord clamping by deferred cord clamping to induce numerous neonatal benefits. But this practice is still resisted in most of the Arab countries. The aim of this study was to evaluate the effectiveness of deferred versus early umbilical cord clamping on maternal and neonatal outcomes. Methods: A quasi experimental research design was utilized. The study was conducted at labour unit in Damanhour National Medical Institute. Sample: A convenience sample of 150 parturient women undergoing normal vaginal delivery were randomly divided in two groups; deferred cord clamping $(\mathrm{n}=75)$ and early cord clamping $(\mathrm{n}=75)$. Tools: Three tools were used for data collection; 1) Structured interview schedule to collect data about the women' demographic characteristics and reproductive history. 2) Maternal outcomes assessment sheet. 3) Neonatal outcomes assessment sheet to assess the immediate and late neonatal outcomes. Results: There were no statistically significant differences ( $\mathrm{P}>0.05$ ) between deferred and early cord clamping groups in relation to the maternal risk for post-partum hemorrhage, duration of third stage of labour and the need for manual removal of the placenta. Furthermore, a highly statistically significant differences $(\mathrm{p}<0.001)$ were observed regarding neonatal hemoglobin, hematocrit, and red blood cells between the two groups. The mean total bilirubin level was significantly higher $(\mathrm{P}<0.05)$ in the deferred cord clamping group than early cord clamping group. Conclusion: The study concluded that deferred umbilical cord clamping did not increase the risk of maternal post-partum hemorrhage, duration of third stage of labour or the need for manual removal of the placenta. Also, deferred cord clamping significantly increased neonatal hemoglobin, hematocrit, and red blood cells level without serious elevation in the total bilirubin level as it was still in the low intermediate risk or below $75^{\text {th }}$ percentile. Recommendation: Institutionalization of deferred cord clamping in all governmental hospitals and medical educational settings through providing policies, procedures and guidelines regarding this practice. This could significantly improve the intra-natal care for the neonate without harmful consequences for the mother.
\end{abstract}

Keywords: deferred cord clamping, full term newborns, maternal and neonatal outcomes, placental transfusion

Cite This Article: Wafaa Taha Ibrahim Elgzar, Heba Abdel-Fatah Ibrahim, and Hanan Heiba Elkhateeb, "Effects of Deferred Versus Early Umbilical Cord Clamping on Maternal and Neonatal Outcomes." American Journal of Nursing Research, vol.5, no. 4 (2017): 115-128. doi: 10.12691/ajnr-5-4-3.

\section{Introduction}

Third stage of labour starts with the complete fetal expulsion until the expulsion of the placenta. Management of the third stage of labour is the key of safe fourth stage of labour and post-partum period. After scattered trials to decrease the risk for Post-Partum Hemorrhage (PPH), one intervention composed of three parts had been identified by the world health organization (WHO) as reducing the risk for $\mathrm{PPH}$. This intervention composed of administration of uterotonic drugs after delivery of the baby, early cord clamping (ECC) and cutting and controlled cord traction. The WHO had integrated this intervention as active management of the third stage of labour (AMTSL) [1]. Later on, numerous researches had been done to evaluate the effectiveness of each component of AMTSL [2,3]. The administration of uterotonic drugs had been identified as the most important component of the intervention [4]. While the benefits of ECC and controlled cord traction are still controversial.

The WHO had conducted many trials and demonstrated that controlled cord traction and ECC didn't add any benefits to the prevention of Post-Partum Hemorrhage. It may affect the duration of third stage of labour, which is an important issue for busy staff in the delivery room [3]. Consequently, the WHO modified the AMTSL to include: first, administration of uterotonic drugs immediately after delivery of the fetus. The preferred uterotonic drug is oxytocin. Second, deferred cord clamping (DCC) for at least 1-3 minutes to reduce infant anemia and controlled cord traction conducted only if required. Third, postpartum vigilance which means immediate assessment 
of the uterus to ensure contracted uterus every 15 minutes until two hours (fourth stage of labour). If there is uterine atony perform fundal message and monitor more frequently [5].

Recently the use of the term 'deferred' cord clamping has been recommended as this suggests a planned policy in contrast to the term 'delayed' cord clamping which may imply that the cord is clamped later than the ideal time [6]. Polices regarding timing of cord clamping is varies from country to another or even from health facility to another within the same country. ECC means clamping and cutting it within time from birth to less than 30 seconds from the delivery. Where, DCC means to delay clamping of the cord greater than one minute to maximum 5 minutes after delivery of the baby or when the cord pulsation has ceased [1]. Some studies considered DCC if it was cut after 30 seconds [7].

The physiology of placenta transfusion is easy to be predicted as the importance of placenta to the baby is well understood. Around the 18 to 20 weeks of pregnancy the blood is equally divided between the infant and placenta. At birth around one third of the blood is retained in the placenta. ECC deprives the fetus from $20-35 \mathrm{ml}$ of blood for each kilogram of its body weight. If the cord clamping is deferred and placenta transfusion is completed, the plasma volume is decreased after several hours, leaving large number of Red Blood Cells (RBCs). Those RBCs are destroyed leaving both bilirubin and large amount of iron. DCC results in $20-30 \mathrm{mg} / \mathrm{kg}$ of iron, which is enough for the fetus need for at least three months. On the other hand, the resulting bilirubin will lead to increased risk for jaundice requiring phototherapy [6]. Furthermore, immediately after birth the fetal pulmonary vascular resistance rapidly decreased and the placenta circulation slows. This situation improves the pulmonary blood flow and helps the fetus to go safe transition from fetal to neonatal circulation. It also helps the baby oxygen saturation and the establishment of circulatory functions. Early clamping of the cord may deprive the neonate from such benefits. DCC for a short period can increase the neonatal blood volume while longer delay can help in the stabilization of the neonatal Blood Pressure(BP) and better cardiopulmonary circulation [8]. McDonald and Middleton conducted a systemic review about studies evaluated the DCC until December 2007. They concluded that DCC did not increase the risk for $\mathrm{PPH}$, but it can be advantageous for the infant by improving its iron storage. On the other hand, one study reported that delaying the cord clamping increases the risk of jaundice requiring phototherapy [9].

The WHO stated that DCC is recommended for all births while initiating simultaneous newborn care. E is not recommended unless the newborn require removal for resuscitation. If resuscitation is applicable while the cord is intact, it will give better results. Furthermore, it is strongly acknowledged that if the newborn did not take breathing spontaneously it is better to leave the cord intact so he can take oxygen from the placenta until he can breathe. This will help the newborn cardio-pulmonary adaptation [10]. Some studies had emphasized the great benefits of DCC for the preterm fetus. They argued that DCC can produce high pulmonary artery pressure, which may be protective against fluctuating cerebral blood flow by reducing ductal shunt [11]. DCC also suspected to improve the cerebral blood flow and oxygen carrying capacity of the blood by increasing the numbers of RBCs [12]. Another placenta blood component that could be beneficial especially for preterm or term infant is the stem cells. Baenziger concluded that the cord stem cells could benefit the newborn immediately after birth through improving their respiratory functions, oxygen saturation and decrease the risk for intraventricular hemorrhage and sepsis. As well increase hemoglobin level and the immunity. Later on, the placenta stem cells are likely to decrease the risk of apnea of prematurity, retinopathy of prematurity and enterocolitis. At adult life, the placenta stem cells can protect the person from many chronic and immunological diseases [13]. Jason and his colleagues had conducted systemic review about the placenta stem cells. They surveyed 22 studies conducted between 2010 and 2014, and concluded that the placenta is natural and unique feto-maternal organ. It contains unaccountable types of stem cells that not only beneficial to the newborn, but also can be used for transplantation to treat various immunological diseases and cancers in children and adults. They further reported that the stem cells isolated from the placenta have special characteristics such as high expansion rate, its differentiation capabilities, safety and efficiency. Consequently, the placenta stem cells will have great potentials in regenerative medicine and immune-modulation functions [14].

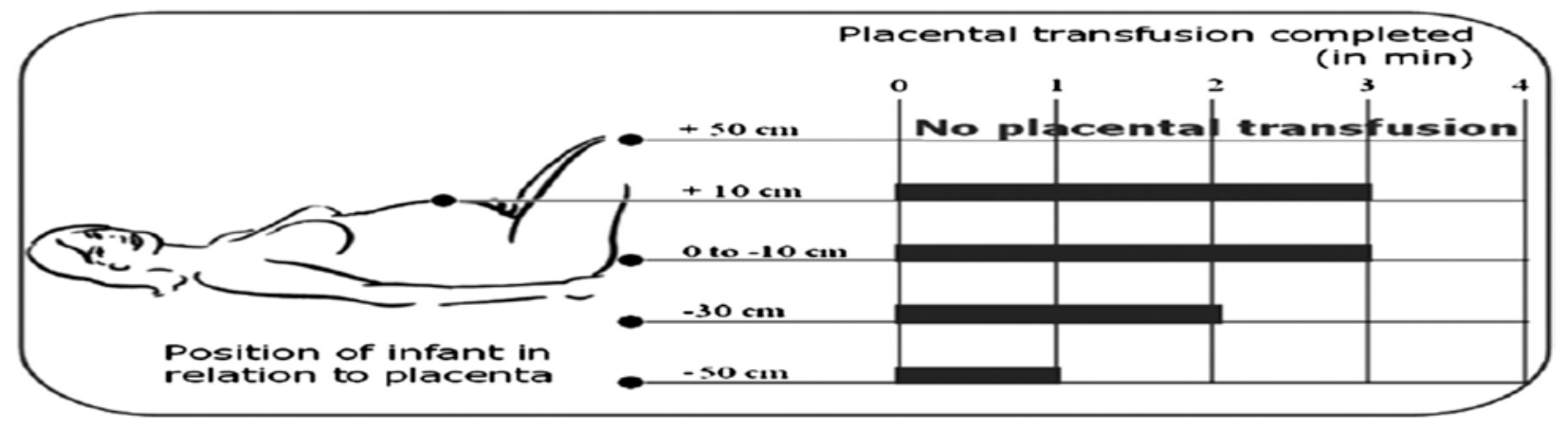

Figure 1. the influence of gravity on the rate and timing of placenta transfusion

Source: Kim, A.J., \& Warren, J.B. Optimal Timing of Umbilical Cord Clamping: Is the Debate Settled? Part 2 of 2: Evidence in Preterm and Term Infants, Alternatives, and Unanswered Questions. APP news journal. 2015; 16(5). 
The rate of the placenta transfusion is strongly affected by some factors. Those factors include gravity, the use of uterotonic drugs during the third stage of labour and the mode of delivery. The first factor that affect placenta transfusion is the gravity. As the umbilical vein carries the oxygenated blood from the placenta to the fetus while the umbilical artery carry the non-oxygenated blood from the fetus to the placenta. Raising the fetus above the level of the placenta is expected to slow the blood transfusion via the umbilical vein while enhancing the blood transfusion via the umbilical artery back to the placenta. On the other hand, putting the newborn at a lower level than the placenta may speed the blood flow from the placenta to the baby without apparent effect on the total blood volume transfused [6]. No sufficient evidences correlate between the effect of gravity on the umbilical cord transfusion and the administration of Oxytocin. Kim and Warren conducted a study to determine the optimal time for umbilical cord clamping in correlation with the fetal position above or below the placenta level. (Figure 1) They concluded that holding the fetus $50 \mathrm{~cm}$ above the level of placenta will completely hinder the placenta transfusion while if it is held 0 to $10 \mathrm{~cm}$ above the placenta transfusion will be completed within three minutes. The effect of gravity appears more obvious if the fetus is held $30 \mathrm{~cm}$ below the level of the placenta as the placenta transfusion will be completed within 2 minutes. Furthermore, holding the fetus $50 \mathrm{~cm}$ below the placenta will help placenta transfusion to be completed within one minute only. The latter choice is excellent for busy delivery rooms and cesarean section where fast intervention is required [15].

The second factor that can affect the rate and timing of the placenta transfusion is the administration of uterotonic drugs. The ergometrine given intravenous will have rapid action on the uterine contractility within 10 seconds. Consequently, it may affect the speed of placenta transfusion and leads to completion of placenta transfusion within one minute while the volume of blood transfused will not be altered. Intra venous ergometrine is no longer used in AMTSL because of its severe side effects [6]. Intra-muscular oxytocin is the recommended uterotonic drug used in AMTSL by WHO [5]. Oxytocin given IM at delivery of the anterior shoulder will begin to produce uterine contractility 2.5 minutes later, so it will not have an obvious effect on the rate of placenta transfusion. In conclusion, the use of prophylactic uterotonic drugs during the AMTSL is extremely important in prevention of $\mathrm{PPH}$, but it seems to have no benefits in the placenta transfusion when using intramuscular oxytocin [6].

The third factor that may affect the rate of placenta transfusion is the mode of delivery. A recent Australian study conducted by Andersson et al., had compared the effect of DCC for 30 seconds for elective cesarean section with both vaginally delivered births with DCC and vaginally delivered births with ECC. They measured Ferritin and hemoglobin at birth, 48-96 hours post birth, 4 months of age and at one year. They also assessed the respiratory distress at one and six hours after birth. They concluded that DCC for 30 seconds at cesarean section have the same effect as vaginal births with DCC and better than vaginal birth with ECC in all parameters measured.
Furthermore, the three group parameters were similar at one year of age. While more studies are required to evaluate the effect of DCC at cesarean section [16].

Cord milking (stripping) before or after the cord is clamped also used as an alternative to deferred cord clamping. Cord milking leads to rapid pushing of the cord blood (20-30 cm length stropped three times two second a part) to the fetal circulation accompanied with some epithelial tissues. So, further researches are needed to evaluate the benefits or harmful effect of cord milking [17]. However, some studies had compared the effect of cord stripping versus immediate or DCC for preterm or full term births $[18,19]$. They concluded that cord milking improved the neonatal cardiovascular stability, oxygen saturation and reduced the risk for blood transfusion. But more studies are needed to confirm these results.

\subsection{Significance of the Study}

DCC is not universally accepted until now as for the past two centuries ECC was considered a part of AMTSL. A controversial studies are persist regarding the exact time for cord clamping. One survey conducted on 1175 units in 14 European countries concluded that two-thirds of the surveyed units practice ECC as routine [20]. Although WHO and the International Federation of Gynecology and Obstetrics no longer support the ECC as a part of the AMTSL. Furthermore, DCC may play an important role in the reduction of anemia during infancy. In Egypt, according to the results of a recent study conducted by Hassan et al, 57.1\% of infants in Menoufia -Egypt- have iron deficiency anemia [21]. In spite of that, most of the health care providers in the developing countries including Egypt still have resistance for deferred cord clamping. They urged their point of view that jaundice is also a serious problem that should be prevented. This resisting altitude requires conduction of more researches that evaluate the benefits versus the risks of DCC versus ECC. This study will reveal whether the DCC has more positive neonatal outcomes without maternal complication or not. This information would gear the intra-natal care to utilize the effective one. The utilization of DCC would improve the childbirth outcomes on both maternal and neonatal side.

\subsection{Aim of the Study}

The aim of this study was to evaluate the effectiveness of deferred versus early umbilical cord clamping on maternal and neonatal outcomes.

\subsection{Study Hypotheses}

H0: Parturient women and their full term newborns who are exposed to DCC exhibits the same maternal and neonatal outcomes as those who exposed to ECC.

H1: Parturient women and their full term newborns who are exposed to DCC exhibits more positive maternal and neonatal outcomes than those who exposed to ECC.

H2: Parturient women and their full term newborns who are exposed to ECC exhibits more positive maternal and neonatal outcomes than those who exposed to deferred cord clamping. 


\subsection{Operational Definitions}

\subsubsection{Maternal Outcomes}

Refers to the duration of the third stage of labour, amount of blood loss during the third and fourth stage of labour, need for manual removal of the placenta, incidence of post-partum hemorrhage and the need for iron therapy during post-partum period.

\subsubsection{Neonatal Outcomes}

a. Immediate neonatal outcomes: Refer to oxygen saturation at birth, temperature, pulse and BP at birth, BP at four hours after birth, Apgar score at 1 and 5 minutes after birth, and the need for oxygen therapy.

b. Late neonatal outcomes: Refers to oxygen saturation, hematological parameters (HB, RBCs, HCT, WBCs), total bilirubin level at the $6^{\text {th }}$ day after birth, and the need for admission to the Neonatal Intensive Care Unit (NICU).

1.4.3. Early cord clamping: Is considered when the cord is clamped within 30 second after delivery.

1.4.4. Deferred cord clamping: Is considered when the cord is clamped at least 2 minutes or after cord pulsation is ceased.

\section{Subjects and Methods}

\subsection{Research Design}

A quasi-experimental research design was utilized to conduct this study.

\subsection{Setting}

The study was conducted at labour unit in Damanhour National Medical Institute affiliated to ministry of health. Damanhour city Elbehira governorate.

\subsection{Sample Type and Criteria}

A convenience sample of 150 parturient women undergoing vaginal delivery were recruited for the study, according to the following inclusion criteria; have a normal pregnancy (free from any chronic illness or any pregnancy induced complications), singleton full term fetus (37-41 weeks of gestation), expected vaginal delivery, vertex presentation, her fetus is normal weight and free from congenital anomalies using ultrasound scanning, and she is willing to participate in the study. Some women were excluded during labour if: complications were developed, the labour was completed using forceps or vacuum, umbilical cord with true node or cord around the neck necessitating immediate clamping and early resuscitation, short cord that interferes with fetal positioning at the required place, neonate have major congenital anomalies that are not diagnosed during pregnancy. The excluded cases were replaced by another eligible cases.

\subsection{Sample Size}

According to Damanhour National Medical Institute statistical center, 2015, flow rate of the parturient women undergo normal vaginal delivery were 1360 women at the end of the year 2015. Ten percent of flow rate (136 women) was selected. Considering dropout during followup, the researcher added $10 \%$ from the 136 women. Thus the sample size was 150 parturient women; the sample was randomly divided into two groups, DCC (75) ECC (75).

\subsection{Tools}

Three tools were used for data collection.

\subsubsection{Tool I: Structured Interview Schedule:}

It consisted of two main parts

Part 1: It included the studied women' demographic data as age, residence, education and occupation.

Part 2: It included the studied women' reproductive and medical history as gravidity, parity, gestational age, history of PPH, and maternal hemoglobin before delivery.

\subsubsection{Tool II: Maternal Outcomes Assessment Sheet}

It included five items: duration of the $3^{\text {rd }}$ stage of labour, amount of blood loss during labour, need for manual removal of the placenta, need for blood transfusion, and the need for iron therapy after delivery.

\subsubsection{Tool III: Neonatal Assessment Sheet}

It included three parts:

Part 1: Immediate neonatal outcomes: oxygen saturation at birth, temperature, pulse and BP at birth, BP at four hours after birth, Apgar score at 1and 5 minutes after birth, neonatal weight, and the need for oxygen therapy.

Part 2: Late neonatal outcomes: oxygen saturation, hematological parameters (HB, RBCs, HCT, WBCs), total bilirubin level at the $6^{\text {th }}$ day, and the need for admission to NICU.

Part 3: Bilirubin assessment chart (Figure 2) [22]: This tool is a graphical representation to evaluate the total bilirubin level, this tool divides the total bilirubin at the $6^{\text {th }}$ day of life into one of four categories:

- Normal Low risk below $40^{\text {th }}$ percentile $(\leq 13 \mathrm{mg} / \mathrm{dl})$

- Low intermediate risk ranged from $40^{\text {th }}<75^{\text {th }}$ percentile (13.1- $15.2 \mathrm{mg} / \mathrm{dl})$

- High intermediate risk ranged from $75^{\text {th }}<95^{\text {th }}$ percentile (15.3-17.2 mg/d)

- High risk $95^{\text {th }}$ percentile and more $(17.3 \mathrm{mg} / \mathrm{dl}$ and more)

\subsubsection{Tools Validity}

All tools were tested for content validity by a jury of five expertise in the obstetrics and gynecological nursing and one from biostatistics field.

\subsubsection{Tools Reliability}

Reliability of tools were tested by using Cronbach's Alpha coefficient test, which revealed that the tool II (maternal outcomes assessment sheet) and tool III (Neonatal outcomes assessment sheet) consisted of relatively homogenous items as indicated by high reliability $=0.85$ and 0.87 , respectively. 


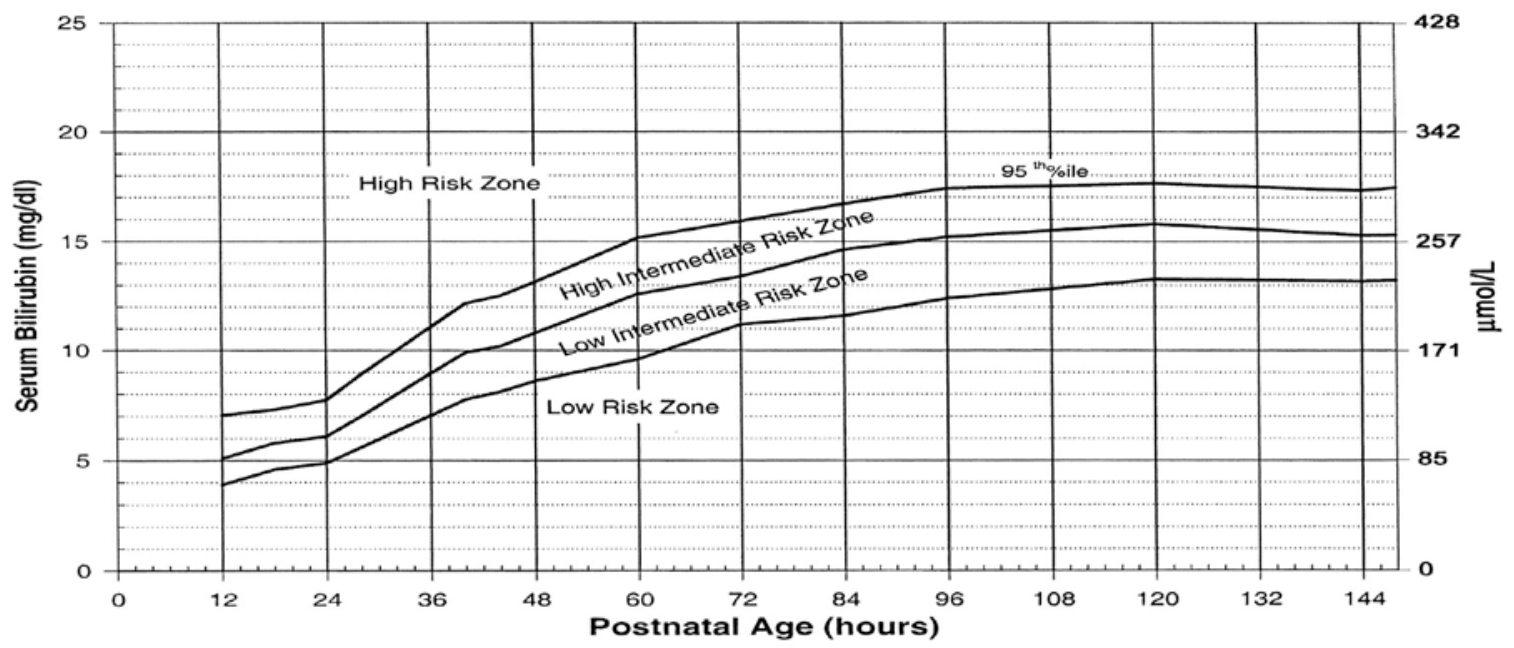

Figure 2. Bilirubin assessment chart (Reference: American academy of pediatrics. Management of Hyperbilirubinemia in the Newborn Infant 35 or More Weeks of Gestation. American journal of pediatrics; 2004:114(1): 297-316.)

\subsection{Pilot Study}

A pilot study was conducted on $10.0 \%$ of the total subjects (15 women) to test the clarity and applicability of the study tools. Participants included in the pilot study were excluded from the study subjects.

\subsection{Ethical Considerations}

Considerations were done to comply with ethical principles in all stages of the study. Primarily, permission was received from Nursing college Damanhour university to conduct the study, then it was approved from Damanhour National Medical Institute. Oral informed consents were attained from every parturient woman recruited in the study after clarification of the nature and the aim of the study. Parturient woman also were informed that their information will be confidential and will be used only for research goal. They were informed about their rights to refuse participation or leave the study at any time.

\subsection{Field Work}

Data were collected from the beginning of July 2016 till the end of December 2016. The current study was carried out through the following phases:

\section{Preparatory phase:}

- At admission of the eligible parturient to the delivery room oral consent was taken from her after explaining the purpose and process of the study.

- Demographic characteristics, reproductive and medical history were collected by using tool I from the women' medical record.

- A suitable movable table for baby care was prepared and covered with a sterile towel. The table level was adjusted to be below the level of the delivery bed by $30 \mathrm{~cm}$. Newborn vital signs tray (electronic thermometer, neonatal stethoscope, BP apparatus with baby calf, and neonatal pulse oximeter ) also was prepared in advance.

\section{Intervention phase:}

A. For the DCC group: which included immediate care for mother and newborn.

1. Immediate care for the newborn:
- Immediately after delivery the movable table was put at the end of delivery table beside the woman's perineum. The baby was put on the table with the cord intact for at least two minutes or until the cord pulsation ceased. The immediate care of the newborn was conducted at the table through pediatrician and one of the researchers. Apgar score was assessed at one and five minutes. The newborn temperature and oxygen saturation were assessed after the first Apgar scoring. The baby temperature was kept using a sterile towel that covers all the baby including the head. After two minutes the cord was clamped and cut. The time elapsed between delivery and cord clamping was calculated using stopwatch by the assistant nurse. Later, the newborn table was removed and the baby transferred to a suitable place to complete his needed procedures. Baby was weighted. BP measured after cord clamping using suitable cuff. Oxygen saturation measured using a suitable pulse oximeter. At 4 hours the newborn BP measured again.

2. Immediate care for the mother:

- Within 15 second after baby expulsion the women injected by 5 IU oxytocin intra-muscular. During the time elapsed between delivery of the baby and cord clamping the women genitalia was examined for tears or laceration. After clamping of the cord the placenta was delivered using controlled cord traction. After delivery of the placenta the uterus was assessed for uterine atony. If atony persist the uterus was massaged. Complete assessment was done for the vagina and perineum for tear needs repair. Also if episiotomy was done repair was completed.

- Calculation of blood loss during birth: a wide basin was prepared in advance for the purpose of putting it under the delivery table to receive blood. A absorbable mackintosh was used to make connection or channel between the woman's perineum and the basin. One edge of the mackintosh was under the woman's buttocks and the other edge down in the basin. The basin weight was taken in advance. Also all linen, mackintosh and cotton sponges used in the labour and become soiled with blood was weighted 
before and after delivery. The net amount of blood loss = the weight of the basin of blood, soiled mackintosh and cotton sponges and contaminated linen after labour - the weight of the same basin, mackintosh, sterile cotton sponges and clean linen before delivery.

\section{B. For the ECC group:}

- The same immediate care for mother and newborn were provided to the ECC group except that the baby cord was clamped and cut within 30 second of birth. Also the immediate baby care completely provided away from the mother.

\section{Follow up phase for the two groups:}

- After 6 hours the mother and her newborn were discharged to home. She is informed to return for follow up if she noted baby any danger signs (yellowish eye sclera, yellowish skin, poor breastfeeding, cord infection signs) or maternal danger signs(bleeding, fever, offensive discharge, severe abdominal pain or perineal pain). If no danger signs appear the women is instructed to come for follow up at the $6^{\text {th }}$ day.

- The neonatal follow up was conducted according to the current study follow up chart (Figure 3).

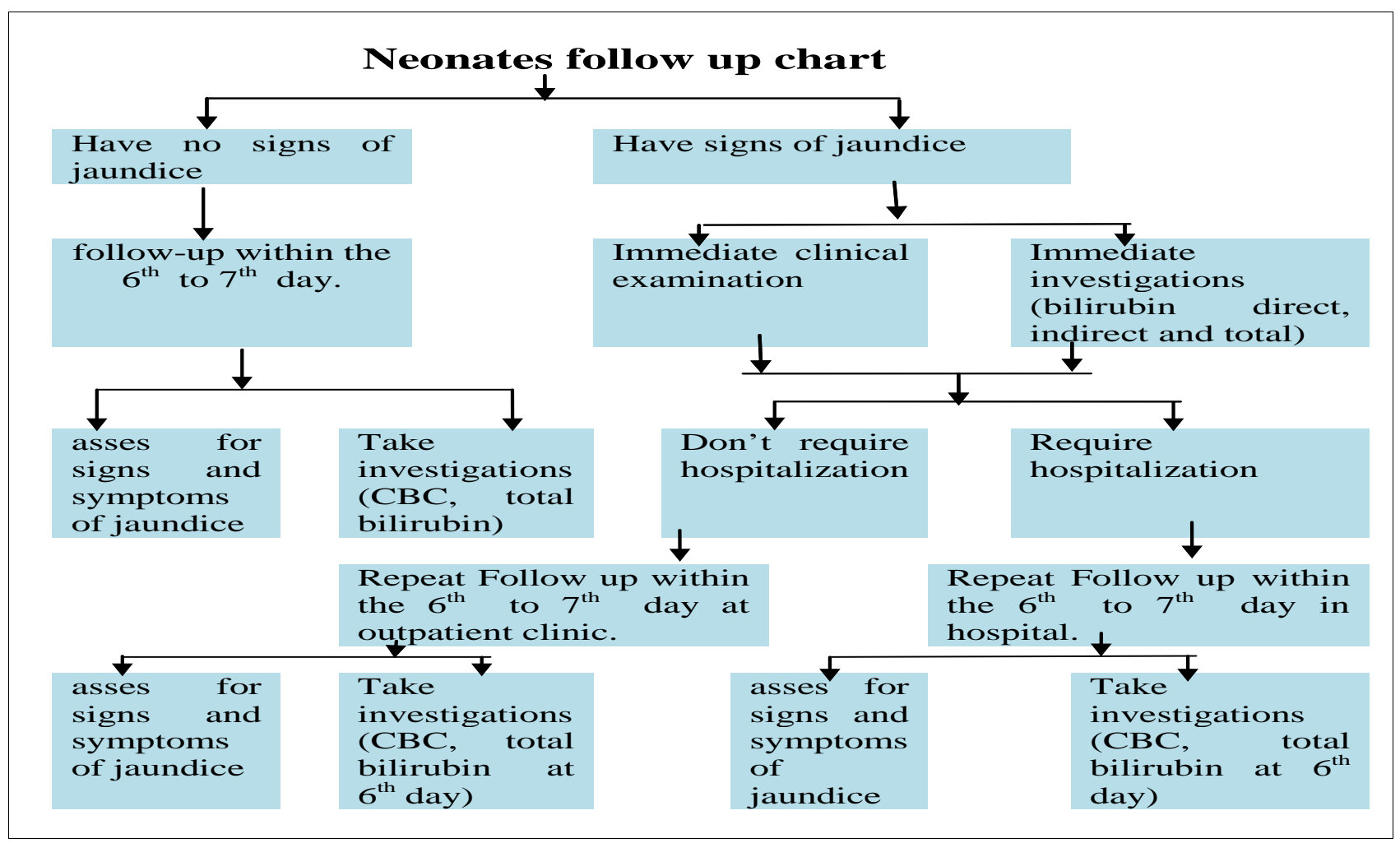

Figure 3. The neonatal follow up chart was designed by the researchers

\subsection{Statistical Analysis}

The Data were analyzed using the statistical package for social sciences (SPSS) version 20.0, then the data were explored. Descriptive statistics (frequency, percentage, arithmetic mean, and standard deviation) were used to describe characteristics of the studied subjects. Qualitative variables were compared using a chi-square test, and Fisher's Exact test (FET) as the tests of significance. Independent (t) test was used to compare between mean differences of the ECC and DCC groups. The p-value is the degree of significance. A statistically significant difference was considered at $\mathrm{p}$-value $\leq 0.05$ and a highly statistically significant difference was considered at p-value $\leq 0.001$. While the p-value $>0.05$ indicates non-significant results.

\section{Results}

Table 1: Shows the demographic characteristics of the parturient women under the study. It was observed that, $65.3 \%$ of DCC group and $53.3 \%$ of ECC group aged $>20$ to $<30$ years, with a mean age $26.05 \pm 4.66$ and
$27.24 \pm 4.82$ years for both groups respectively. In addition, $66.8 \%$ and $68.0 \%$ of them had a basic and secondary education in the deferred and ECC groups respectively. Regarding residence, it was found that, $56.0 \%$ and $66.7 \%$ of deferred and ECC group respectively were urban areas residence. Furthermore, $73.3 \%$ and $78.7 \%$ of deferred and ECC group respectively were housewives. There were no statistically significant differences between the two groups regarding their demographic characteristics.

Table 2: Illustrates the reproductive and medical history of the studied women. It was found that $46.7 \%$ and 49.3\% of DCC and ECC groups respectively were primigravida. The mean numbers of births of the studied women in DCC and ECC groups were $1.81 \pm 1.02$ and $1.78 \pm 1.05$ times respectively. Concerning the history of $\mathrm{PPH}, 81.3 \%$ of DCC group and $84.0 \%$ of ECC group hadn't history of PPH. In addition, the mean maternal hemoglobin level before delivery of both groups were $10.88 \pm 53 \mathrm{~g} / \mathrm{dl}$ and $10.77 \pm 0.46 \mathrm{~g} / \mathrm{dl}$, respectively. There were no statistically significant differences ( $p>0.05$ ) between DCC and ECC groups in the term of gravidity, parity, history of PPH and hemoglobin level. 
Table 1. Number and Percent Distribution of the Study Subjects According to Their Demographic Characteristics (n=150)

\begin{tabular}{|c|c|c|c|c|c|c|}
\hline \multirow[b]{2}{*}{ Demographic characteristics } & \multicolumn{2}{|c|}{ DCC n=75 } & \multicolumn{2}{|c|}{ ECC $n=75$} & \multirow[t]{2}{*}{ Significance test } & \multirow[t]{2}{*}{ P value } \\
\hline & No & $\%$ & No & $\%$ & & \\
\hline \multicolumn{7}{|l|}{ Age } \\
\hline$-\leq 20$ years & 12 & 16.0 & 12 & 16.0 & \multirow{3}{*}{$\mathrm{FET}=3.099$} & \multirow{3}{*}{0.212} \\
\hline - >20- 30 years & 49 & 65.3 & 40 & 53.3 & & \\
\hline - >30 years & 14 & 18.7 & 23 & 34.7 & & \\
\hline Mean \pm SD & \multicolumn{2}{|c|}{$26.05 \pm 4.66$} & \multicolumn{2}{|c|}{$27.24 \pm 4.82$} & $\mathrm{t}=1.530$ & 0.128 \\
\hline \multicolumn{7}{|l|}{ Level of education } \\
\hline - Illiterate & 5 & 6.6 & 6 & 8.0 & \multirow{3}{*}{$\mathrm{FET}=2.08$} & \multirow{3}{*}{0.342} \\
\hline - Basic and secondary education & 50 & 66.8 & 51 & 68.0 & & \\
\hline - University or post graduate & 20 & 26.6 & 18 & 24.0 & & \\
\hline \multicolumn{7}{|l|}{ Residence } \\
\hline - Rural & 33 & 44.0 & 25 & 33.3 & \multirow[t]{2}{*}{$\chi^{2}=1.799$} & \multirow[t]{2}{*}{0.180} \\
\hline - Urban & 42 & 56.0 & 50 & 66.7 & & \\
\hline \multicolumn{7}{|l|}{ Occupation } \\
\hline - House wife & 55 & 73.3 & 59 & 78.7 & \multirow[t]{2}{*}{$\chi^{2}=0.585$} & \multirow[t]{2}{*}{0.444} \\
\hline - Employee & 20 & 26.7 & 16 & 21.3 & & \\
\hline
\end{tabular}

T: Independent sample $t$ test, $\chi^{2}=$ Person chi-square, FET= Fisher Exact Test.

Table 2. Number and Percent Distribution of the Study Subjects According to their Reproductive and Medical History (n=150)

\begin{tabular}{|c|c|c|c|c|c|c|}
\hline \multirow[b]{2}{*}{ Reproductive and medical history } & \multicolumn{2}{|c|}{ DCC $n=75$} & \multicolumn{2}{|c|}{ ECC $n=75$} & \multirow[t]{2}{*}{ Significance test } & \multirow[t]{2}{*}{$P$ value } \\
\hline & No & $\%$ & No & $\%$ & & \\
\hline \multicolumn{7}{|l|}{ Gravidity } \\
\hline - Primi-gravida & 35 & 46.7 & 37 & 49.3 & & \\
\hline$-2^{\text {nd }}$ gravid & 24 & 32.0 & 20 & 26.7 & $\mathrm{FET}=2.156$ & 0.873 \\
\hline$-3^{\text {rd }}$ gravid & 13 & 17.3 & 13 & 17.3 & & \\
\hline - Grand multi gravid & 3 & 4.0 & 5 & 6.7 & & \\
\hline Mean $\pm \mathrm{SD}$ & \multicolumn{2}{|c|}{$1.83 \pm 0.99$} & \multicolumn{2}{|c|}{$1.85 \pm 1.06$} & $\mathrm{t}=0.159$ & 0.874 \\
\hline \multicolumn{7}{|l|}{ Parity } \\
\hline - Primiparas + abortion \# & 37 & 49.3 & 40 & 53.3 & $\chi^{2}=0.240$ & 0.744 \\
\hline - Multiparas & 38 & 50.7 & 35 & 46.7 & & \\
\hline Mean \pm SD & \multicolumn{2}{|c|}{$1.81 \pm 1.02$} & \multicolumn{2}{|c|}{$1.78 \pm 1.05$} & $\mathrm{t}=0.157$ & 0.875 \\
\hline \multicolumn{5}{|l|}{ History of PPH } & $\chi^{2}=0.186$ & 0.666 \\
\hline - Yes & 14 & 18.7 & 12 & 16.0 & & \\
\hline - No & 61 & 81.3 & 63 & 84.0 & & \\
\hline Maternal hemoglobin before delivery( Mean \pm SD) & \multicolumn{2}{|c|}{$10.88 \pm 53$} & \multicolumn{2}{|c|}{$10.77 \pm 0.46$} & $\mathrm{t}=1.43$ & 0.155 \\
\hline
\end{tabular}

t: Independent sample t test, $\chi^{2}=$ Person chi-square, FET= Fisher Exact Test, \#: 2 cases aborted in DCC group and 3 cases in ECC.

Table 3. Comparison Between DCC and ECC Groups Regarding their Maternal Outcomes (n=150)

\begin{tabular}{|c|c|c|c|c|c|c|}
\hline \multirow[t]{2}{*}{ Maternal outcomes } & \multicolumn{2}{|c|}{ DCC $n=75$} & \multicolumn{2}{|c|}{ ECC $n=75$} & \multirow[t]{2}{*}{ Significance test } & \multirow[t]{2}{*}{$P$ value } \\
\hline & No & $\%$ & No & $\%$ & & \\
\hline Duration of the $3^{\text {rd }}$ stage of labour (Mean \pm SD) & \multicolumn{2}{|c|}{$11.29 \pm 2.45$} & \multicolumn{2}{|c|}{$11.62 \pm 2.92$} & $\mathrm{t}=0.755$ & 0.451 \\
\hline \multicolumn{7}{|l|}{ Estimated blood loss during $3^{\text {rd }}$ and $4^{\text {th }}$ stage of labour } \\
\hline - Less than $500 \mathrm{ml}$ & 53 & 70.7 & 57 & 76.0 & \multirow{3}{*}{$\mathrm{FET}=0.546$} & \multirow{3}{*}{0.580} \\
\hline$-500-1000 \mathrm{ml}$ & 22 & 29.3 & 18 & 24.0 & & \\
\hline - More than $1000 \mathrm{ml}$ & 0 & 0.0 & 0 & 0.0 & & \\
\hline \multicolumn{7}{|l|}{ Need for manual removal of the placenta } \\
\hline - Yes & 4 & 5.3 & 2 & 2.7 & \multirow[t]{2}{*}{$\mathrm{FET}=0.707$} & \multirow[t]{2}{*}{0.681} \\
\hline - No & 71 & 94.7 & 73 & 97.3 & & \\
\hline \multicolumn{7}{|l|}{ Need for blood transfusion } \\
\hline - Yes & 3 & 4.0 & 5 & 6.7 & \multirow[t]{2}{*}{$\mathrm{FET}=0.534$} & \multirow[t]{2}{*}{0.719} \\
\hline - No & 72 & 96.0 & 70 & 93.3 & & \\
\hline \multicolumn{5}{|l|}{ Need for iron therapy during post-partum period } & \multirow[t]{2}{*}{$\chi^{2}=0.667$} & \multirow[t]{2}{*}{0.414} \\
\hline - No & 9 & 12.0 & 6 & 8.0 & & \\
\hline
\end{tabular}

t: Independent sample t test, $\chi^{2}=$ Person chi-square, FET= Fisher Exact Test. 
Table 3: Reveals no significant differences ( $\mathrm{P}>0.05)$ between DCC and ECC groups in relation to duration of the $3^{\text {rd }}$ stage of labour, estimated blood loss during $3^{\text {rd }}$ and $4^{\text {th }}$ stage, need for manual removal of the placenta, need for blood transfusion and iron therapy during post-partum period. It was clear that the mean duration of $3^{\text {rd }}$ stage of labour were $11.29 \pm 2.45$ and $11.62 \pm 2.92$ minutes for DCC and ECC groups, respectively. Moreover, $70.7 \%$ and $76.0 \%$ of the DCC and ECC group respectively lost less than $500 \mathrm{ml}$ blood during $3^{\text {rd }}$ and $4^{\text {th }}$ stage of labour. Only $5.3 \%$ and $2.7 \%$ of the DCC and ECC group respectively needed manual removal of the placenta. Small proportion
(4.0\% and 6.7\%) of DCC and ECC group respectively needed blood transfusion. Finally, the majority $(88.0 \%$ and $92.0 \%$ ) of DCC and ECC group needed iron therapy during post-partum period, respectively.

According to Table 4, there were statistically significant differences $(\mathrm{p}<0.05)$ between both DCC and ECC groups regarding their oxygen saturation at birth, neonatal temperature, and systolic BP at 4 hours. On the other hand, no statistically significant differences $(p>0.05)$ were observed between the two groups in relation to oxygen saturation at $6^{\text {th }}$ day, fetal pulse at birth, diastolic BP at birth, diastolic BP at 4 hours and neonatal weight.

Table 4. Comparison Between DCC and ECC Groups Regarding their Neonatal Oxygen Saturation and Vital Signs (n=150)

\begin{tabular}{llccc}
\hline Neonatal oxygen saturation and vital signs. & DCC $\mathbf{n}=\mathbf{7 5}$ & ECC n= 75 & t test & P value \\
& Mean \pm SD & Mean \pm SD & & \\
\hline - $\quad$ Oxygen saturation at birth & $93.14 \pm 2.08$ & $91.89 \pm 3.68$ & 2.562 & $0.011^{*}$ \\
- - Oxygen saturation at 6 th $^{\text {day }}$ & $95.09 \pm 1.55$ & $95.02 \pm 1.02$ & 0.310 & 0.757 \\
- Neonatal temperature & $36.016 \pm 0.65$ & $35.52 \pm 0.78$ & 1.879 & $0.044^{*}$ \\
- Fetal pulse at birth & $149.33 \pm 5.52$ & $147.60 \pm 7.62$ & 1.594 & 0.113 \\
- Systolic BP at birth & $71.92 \pm 13.14$ & $69.50 \pm 12.67$ & 1.144 & 0.254 \\
- Diastolic BP at birth & $44.22 \pm 7.74$ & $43.42 \pm 6.98$ & 0.664 & 0.507 \\
- Systolic BP at 4 hours & $87.05 \pm 5.08$ & $82.73 \pm 10.89$ & 3.113 & $0.002^{*}$ \\
- Diastolic BP at 4 hours & $45.04 \pm 7.62$ & $43.89 \pm 6.96$ & 0.884 & 0.378 \\
- Neonatal weight & $3.27 \pm 0.222$ & $3.32 \pm 0.251$ & 1.446 & 0.150 \\
\hline
\end{tabular}

$\mathrm{t}$ : Independent sample t test, *A statistical significant difference $(\mathrm{p} \leq 0.05)$.

Table 5. Comparison Between DCC and ECC Groups Regarding their Apgar score and Need for Oxygen Therapy (n=150)

\begin{tabular}{|c|c|c|c|c|c|c|}
\hline \multirow[t]{2}{*}{ Neonatal outcomes } & \multicolumn{2}{|c|}{ DCC n=75 } & \multicolumn{2}{|c|}{ ECC $n=75$} & \multirow[t]{2}{*}{ Significance test } & \multirow[t]{2}{*}{ P value } \\
\hline & No & $\%$ & No & $\%$ & & \\
\hline Apgar score at $1^{\text {st }}$ minute & & & & & $\chi^{2}=0.362$ & 0.547 \\
\hline - Normal (7-10) & 70 & 93.3 & 68 & 90.7 & & \\
\hline - Mild distress (4-6) & 5 & 6.7 & 7 & 9.3 & & \\
\hline Mean \pm SD & \multicolumn{2}{|c|}{$9.34 \pm 1.19$} & \multicolumn{2}{|c|}{$8.96 \pm 1.35$} & $t=1.860$ & 0.065 \\
\hline \multicolumn{7}{|l|}{ Apgar score at $5^{\text {th }}$ minute } \\
\hline - Normal (7-10) & 75 & 100.0 & 75 & 100.0 & & \\
\hline Mean \pm SD & \multicolumn{2}{|c|}{$9.85 \pm 0.39$} & \multicolumn{2}{|c|}{$9.80 \pm 0.46$} & $t=0.822$ & 0.413 \\
\hline Need oxygen therapy & & & & & $\chi^{2}=8.43$ & 0.006* \\
\hline - Yes & 18 & 24.0 & 35 & 46.7 & & \\
\hline - No & 57 & 76.0 & 40 & 53.3 & & \\
\hline
\end{tabular}

t: Independent sample t test, $\chi^{2}=$ Person chi-square, $*$ A statistical significant difference $(\mathrm{p} \leq 0.05)$.

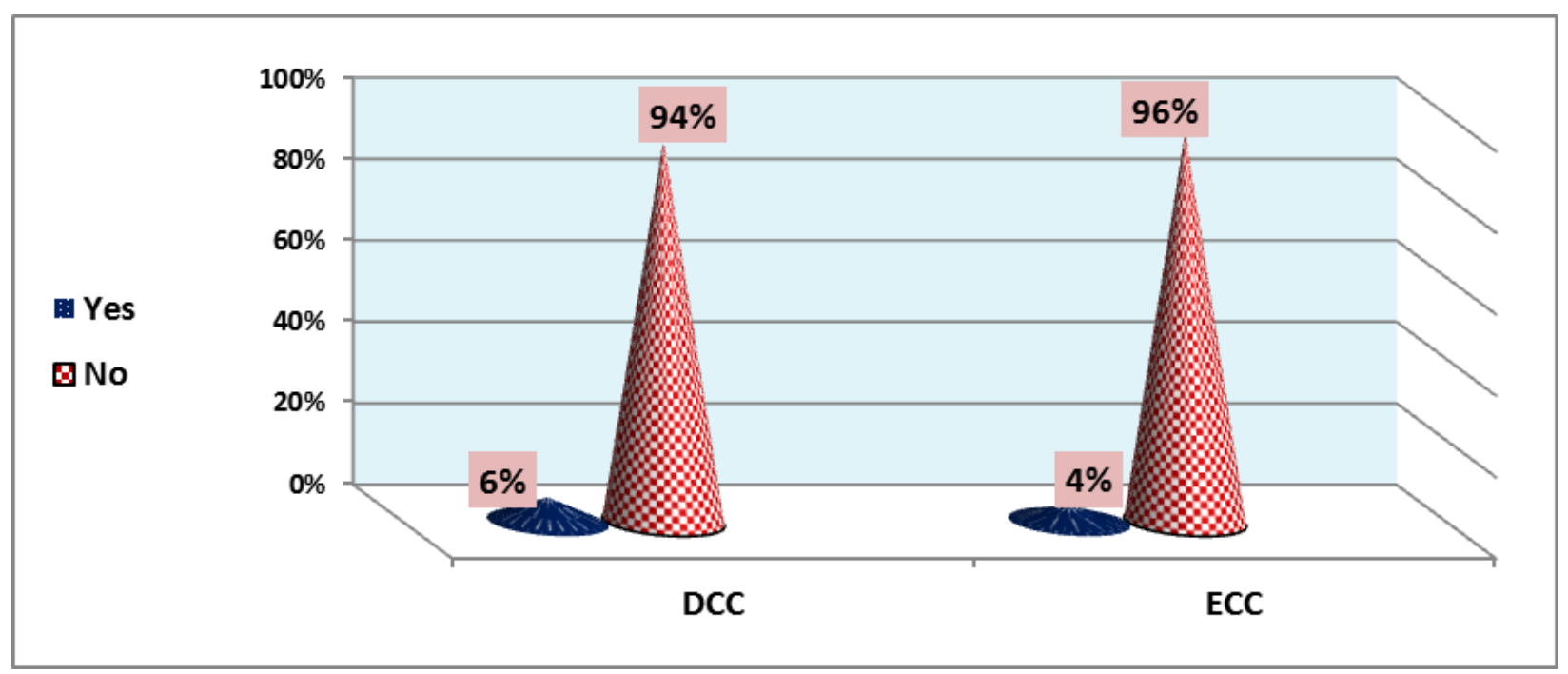

$$
\chi^{2}=0.667(P=0.588)
$$

Figure 4. Comparison Between Deferred and ECC Groups Regarding Neonatal Need for Admission to NICU. 
Table 6. Comparison Between DCC and ECC Groups Regarding the Neonatal Investigations at $6^{\text {th }}$ Day of Age (n=150)

\begin{tabular}{|c|c|c|c|c|c|c|}
\hline \multirow[t]{2}{*}{ Neonatal investigation } & \multicolumn{2}{|c|}{ DCC $n=75$} & \multicolumn{2}{|c|}{ ECC $n=75$} & \multirow[t]{2}{*}{ Significance test } & \multirow[t]{2}{*}{$P$ value } \\
\hline & No & $\%$ & No & $\%$ & & \\
\hline Neonatal Hb & & & & & $\mathrm{FET}=40.153$ & $0.000^{* *}$ \\
\hline$-<14 \mathrm{~g} / \mathrm{dl}$ & 11 & 14.7 & 48 & 64 & & \\
\hline - 14-18 g/dl & 62 & 82.7 & 27 & 36 & & \\
\hline - >18 g/dl & 2 & 2.6 & 0 & 0 & & \\
\hline Mean \pm SD & \multicolumn{2}{|c|}{$15.28 \pm 1.48$} & \multicolumn{2}{|c|}{$13.08 \pm 1.83$} & $t=8.112$ & $0.000^{* *}$ \\
\hline HCT & & & & & $\mathrm{FET}=24.780$ & $0.000^{* *}$ \\
\hline$-<43$ & 36 & 48 & 60 & 80 & & \\
\hline$-43-56$ & 34 & 45.3 & 11 & 14.7 & & \\
\hline - >56 & 5 & 6.7 & 4 & 5.3 & & \\
\hline Mean \pm SD & \multicolumn{2}{|c|}{$43.13 \pm 7.96$} & \multicolumn{2}{|c|}{$36.06 \pm 7.20$} & $t=5.804$ & $0.000^{* *}$ \\
\hline RBCs & & & & & $\chi^{2}=24.020$ & $0.000^{* *}$ \\
\hline$-4.8 \times 10^{6}-5.5 \times 10^{6} \mathrm{M} / \mathrm{UL}$ & 10 & 13.3 & 38 & 50.6 & & \\
\hline - >5.5x10 $\mathrm{M} / \mathrm{UL}$ & 65 & 86.7 & 37 & 49.4 & & \\
\hline Mean \pm SD & \multicolumn{2}{|c|}{$6.06 \pm 0.47$} & \multicolumn{2}{|c|}{$5.42 \pm 0.39$} & $t=8.925$ & $0.000^{* *}$ \\
\hline WBCs & & & & & $\chi^{2}=0.597$ & 0.608 \\
\hline$-<6000$ & 7 & 9.3 & 10 & 13.3 & & \\
\hline$-6000-10000$ & 68 & 90.7 & 65 & 86.7 & & \\
\hline Mean \pm SD & \multicolumn{2}{|c|}{$7514.66 \pm 1196.01$} & \multicolumn{2}{|c|}{$7337.33 \pm 1128.95$} & $\mathrm{t}=0.934$ & 0.352 \\
\hline Total bilirubin & & & & & $\mathrm{FET}=6.179$ & $0.029 *$ \\
\hline - Normal Low risk below $40^{\text {th }}$ percentile $(\leq 13 \mathrm{mg} / \mathrm{dl})$ & 42 & 56.0 & 56 & 74.7 & & \\
\hline $\begin{array}{l}\text { - Low intermediate risk ranged from } 40^{\text {th }} \text { and }< \\
75^{\text {th }} \text { percentile }(13.1-15.2 \mathrm{mg} / \mathrm{dl})\end{array}$ & 9 & 12.0 & 4 & 5.3 & & \\
\hline $\begin{array}{l}\text { - High intermediate risk ranged from } 75^{\text {th }}-<95^{\text {th }} \text { percentile } \\
(15.3-17.2 \mathrm{mg} / \mathrm{dl})\end{array}$ & 19 & 25.3 & 13 & 17.3 & & \\
\hline - High risk above $95^{\text {th }}$ percentile (17.3and more $\mathrm{mg} / \mathrm{dl}$ ) & 5 & 6.7 & 2 & 2.7 & & \\
\hline Mean \pm SD & \multicolumn{2}{|c|}{$13.89 \pm 2.22$} & \multicolumn{2}{|c|}{$12.66 \pm 3.12$} & $t=2.768$ & $0.006^{*}$ \\
\hline
\end{tabular}

t: Independent sample $t$ test, $\chi^{2}=$ Person chi-square, FET= Fisher Exact Test.

*A statistical significant difference $(\mathrm{p} \leq 0.05),{ }^{*}$ A highly statistical significant difference $(\mathrm{p} \leq 0.001)$.

Table 5: shows a statistically significant differences $(p<0.05)$ between the two groups regarding their need for oxygen therapy. While no statistically significant differences $(\mathrm{P}>0.05)$ were observed regarding Apgar score at $1^{\text {st }}$ or $5^{\text {th }}$ minute among DCC and ECC groups. The mean Apgar score at the $1^{\text {st }}$ minute was $9.34 \pm 1.19$ and $8.96 \pm$ 1.35 for DCC and ECC groups, respectively. While, the mean Apgar score at $5^{\text {th }}$ minute was $9.85 \pm 0.39$ and $9.80 \pm$ 0.46 for DCC and ECC groups, respectively.

Figure 4: portrayed that there was no statistical significant difference $(\mathrm{P}=0.588)$ observed among DCC and ECC groups regarding the neonatal need for admission to NICU.

Table 6: presents a comparison between DCC and ECC groups regarding the neonatal investigations at $6^{\text {th }}$ day of age. There were highly statistically significant differences $(\mathrm{p}<0.001)$ regarding neonatal $\mathrm{Hb}, \mathrm{HCT}$, and RBCs at $6^{\text {th }}$ day of age. While there was no statistically significant difference $(P>0.05)$ regarding their WBCs. The total bilirubin at $6^{\text {th }}$ day of age significantly differ between DCC and ECC group. Three quarters (74.7\%) of the ECC group had normal bilirubin level at $6^{\text {th }}$ days of age compared to $56 \%$ among the DCC group. Only $6.7 \%$ of the DCC group had bilirubin level above the $95^{\text {th }}$ percentile compared to $2.7 \%$ among the ECC group. Where, the total bilirubin mean was significantly higher $(\mathrm{P}<0.05)$ in the DCC group than in ECC group, $13.89 \pm 2.22 \mathrm{mg} / \mathrm{dl}$ and $12.66 \pm 3.12 \mathrm{mg} / \mathrm{dl}$, respectively.

\section{Discussion}

By each delivery, obstetricians or midwives decide when to clamp and cut the umbilical cord. ECC has become the routine practice as a part of active management of the third stage of labour in the developed world without scientific assessment of its potential impact on a newborn's health and development. Furthermore, ECC as a part of the active management of the third stage of labour is believed to significantly decrease the risk of $\mathrm{PPH}$. Since many active management protocols include ECC, leading some to imply that DCC may increase the risk for $\mathrm{PPH}$. On the contrary, recent protocol proposed by WHO to manage the third stage of labour replaced the ECC by DCC to induce numerous neonatal benefits. However, delayed versus immediate cord clamping is not universally accepted as part of the management of the third stage of labour [23]. In addition, Fear of polycythemia and hyperbilirubinemia are concerns that have hindered the practice of DCC as routine care [24].

The current study results pointed out that there was no significant difference between DCC and ECC groups in relation to estimated blood loss during $3^{\text {rd }}$ and $4^{\text {th }}$ stage of labour. Whereas, more than two-thirds of the DCC group compared to more than three quarters of ECC group lost normal amount of blood during $3^{\text {rd }}$ and $4^{\text {th }}$ stage of labour 
(blood loss $<500 \mathrm{ml}$ ). Severe PPH (blood loss $>1000 \mathrm{ml}$ ) was not detected in the both groups.

The results of this study are consistent with the results of at least three other studies, which showed no benefit of ECC for the prevention of PPH. First, Backes et al. [25] who studied "the effect of early versus delayed umbilical cord clamping in infants with congenital heart disease". They reported that no significant differences were observed between the two groups in relation to the amount of blood loss during the third and fourth stage of labour. Second, Chidre and Chirumamilla [26] who had conducted a randomized controlled trial about "the impact of early versus delayed umbilical cord clamping on post-partum blood loss". They concluded that post-partum blood loss in early and delayed cord clamping groups was nearly similar. Third, Andersson et al. [27] who had evaluated "the effects of delayed compared with early umbilical cord clamping on maternal PPH and cord blood gas sampling”. They stated that, the differences between the DCC and ECC groups with regard to $\mathrm{PPH}$ were small and non-significant.

The results of the present study are also supported by three systematic reviews and meta-analysis studies which are Dauda and Muhammad; McDonald et al ; McDonald, and Middleton.[28,29,30] all of them have shown no significant differences between delayed and immediate umbilical cord clamping techniques in the incidence and severity of PPH and other maternal complications.

On the contrary, a very old study conducted by Prendiville et al. [31] has suggested that DCC may increase the risk of PPH compared with ECC. No recent trials had been found in this respect.

The current study results revealed that there were no significant differences were observed between DCC and ECC groups in relation to the duration of the $3^{\text {rd }}$ stage of labour and the need for manual removal of the placenta. These findings are in the same line with the previously mentioned study conducted by Chidre and Chirumamilla [26]. They concluded that the timing of cord clamping and cutting has no impact on the duration of the $3^{\text {rd }}$ stage of labour. Furthermore, another two systemic reviews in 2013 surveyed 20 studies (5 for Andersson and 15 for McDonald et al.) [32,33] have supported the recent study results. All the 20 studies reviewed in those two systemic reviews found no significant differences between DCC and ECC groups in relation to their maternal outcomes. Some of those studies included the duration of the third stage of labour and blood loss. Some others included also the need for manual removal of the placenta and the need for blood transfusion. Moreover, Abalos [34] who had studied "the effect of timing of umbilical cord clamping of term infants on maternal and neonatal outcomes" didn't find any significant difference between the two groups in respect to the duration of the $3^{\text {rd }}$ stage of labour. Another systemic review conducted by McDonald et al. [9] surveyed 5 studies related to the effect of timing of umbilical cord clamping on the infant and maternal outcome agreed with the current study result. They concluded that the timing of cord clamping and cutting have no effect on the amount of blood loss during labour, duration of third stage or need for manual removal of the placenta. Some relevant literatures also support the hypothesis that placental transfusion through DCC may decrease the duration of the $3^{\text {rd }}$ stage of labour, since drainage of the placental bed may enhance placenta separation and facilitate its delivery and consequently decreased the need for manual removal of the placenta and $\mathrm{PPH}[35,36]$.

On the contrary, the previously mentioned Ahmad et al. [37] study, showed that the duration of $3^{\text {rd }}$ stage of labour took longer time in the DCC group compared to ECC group with statistical significance difference between the two groups. He did not mention significant difference in relation to the need for manual removal of the placenta or the need for blood transfusion. Again, no other contradictory studies were available regarding this issue. The difference between the recent study and the last one may be attributed to the old fixed believe that ECC is an essential part of active management of the third stage of labour, so if it was delayed it may lead to longer third stage and increase the risk for $\mathrm{PPH}$.

Regarding neonatal outcomes among both groups, the present study revealed that there were statistically significant improvement regarding oxygen saturation at birth, neonatal temperature at birth, and systolic BP 4 hours after birth in the DCC group compared with ECC group. This result is congruent with the results of at least four other researches. First, Jelin et al. [38] who had implemented "Clamp late and maintain perfusion policy for singleton infants $<35$ weeks gestation". They showed that, newborns delivered post-policy implementation had a significant increased and improved temperatures compared with newborns delivered pre-implementation. Second, Fawzy et al. [39] they conducted their study in Egypt to "compare the possible benefits and harms of early versus late clamping in term infants". They found significant improvement in oxygen saturation when the umbilical cord clamping was delayed. Third, Katheria et al. [19] who had conducted a study entitled "umbilical cord milking improves transition in premature infants at birth". Where umbilical cord milking is an alternative to DCC. They pointed out that the improvement in oxygen saturation have been shown with umbilical cord milking group compared with ECC group. The fourth, Kugelman et al. [40] who had studied "immediate versus delayed umbilical cord clamping in premature neonates”. They stated that there was an evidence for improved cardiovascular stability, with higher mean BP at 4 hours after birth in delayed cord clamping group. Rabe et al. [12] had attributed these improvements of enhancing oxygenation through the transfusion of oxygenated blood from the placenta, better control of BP following greater placental transfusion and providing additional blood to the baby in DCC group. The Royal College of Obstetrics and Gynecologist further added that, immediately after birth the fetal pulmonary vascular resistance rapidly decreased and the placenta circulation slows. This situation improves the pulmonary blood flow and helps the fetus to go safe transition from fetal to neonatal circulation. It also helps the baby oxygen saturation and establishment of circulatory functions. DCC for short period can increase the fetal blood volume while longer delay can help in stabilization of the fetal BP and better cardiopulmonary circulation [6].

The present study revealed that there was statistical significance differences among both groups in respect the need for oxygen therapy. where the DCC group needs less 
oxygen therapy than the ECC group. The result of the present study is in agreement with at least other three studies. First, Katheria et al. [41] they stated that increasing fetal hemoglobin by placental transfusion through DCC is an extremely effective method of increasing arterial oxygen content, and improving oxygen delivery. Second, Lakshminrusimha and Neurs [42] who had conducted a study entitled "better timing for cord clamping is after onset of lung aeration”. They stated that DCC conserves oxygenation by sustained placental circulation and is valuable if spontaneous respiration is delayed or compromised. Third, the previously discussed Rabe et al. [12] study, stated that DCC group had better pulmonary perfusion and better blood oxygenation.

Furthermore, the present study revealed no statistical significance differences were observed regarding Apgar scores at $1^{\text {st }}$ and $5^{\text {th }}$ minute among deferred and ECC groups. In the same line, a very recent literature review conducted by Katheria et al. [41], surveyed many previous studies related to this study subject. They concluded that there were no evidences of differences in Apgar score on admission to the newborn unit in studies of term or preterm newborns with ECC versus DCC. Also, Strauss et al. [43] who had conducted "a randomized clinical trial to compare immediate versus delayed clamping of the umbilical cord in preterm infants" reported that the DCC had no measureable effect on Apgar scores at 1 and 5 minutes after delivery, possibly because the time interval between clamping the cord and Apgar scoring was too short to permit expression of possible favorable or adverse effects.

Additionally, the current study had reported that no significant difference was observed regarding the rate of NICU admission among the two groups. In this regard Gamal et al. and Garofalo and Abenhaim [23,44] had similar result to the present study. where is the former, had conducted a study to evaluate "the effect of clamping time on mothers and their full term newborns". They reported no significant difference in the neonatal need for admission to NICU between early and late cord clamping groups. The latter, conducted systemic review about "early versus delayed cord clamping in term and preterm births". They concluded that there were no differences in the rates of respiratory distress or in the rate of NICU admission in ECC group compared to the DCC group in healthy term infants.

A comparison between DCC and ECC groups regarding neonatal hematological parameters at $6^{\text {th }}$ day of age, was took place in the current study. Accordingly, there were a highly significant increase in neonatal hemoglobin, hematocrit, and red blood cells count at $6^{\text {th }}$ day of age in DCC group compared with ECC group. These findings are similar to the findings of four other studies. First Garabedian et al. [45] who had conducted a study to determine "the benefits of DCC in red blood cell alloimmunization". They highlighted that DCC was associated with an improvement in the hemoglobin level at birth and longer delay between birth and first transfusion with no severe hyperbilirubinemia. Second, McDonald et al. [29] who had investigated "the effect of timing of umbilical cord clamping of term infants on maternal and neonatal outcomes". They concluded that, DCC increases early hemoglobin concentrations and iron stores in term infants. Third, Raju [46] in his study entitled "timing of umbilical cord clamping after birth for optimizing placental transfusion”. He mentioned that DCC between 30 and 180 second after birth results in higher concentrations of hematocrit and hemoglobin during the neonatal period, and a decrease prevalence of irondeficiency anemia at 4-6 months of age. Fourth, Strauss et al. [43] who had conducted a randomized clinical trial to "compare immediate versus delayed clamping of the umbilical cord in preterm infants". They showed a significant increase in RBC volume and mass, in delayed umbilical cord clamping group compared to ECC group.

Some relevant literatures are also agree with the current study results. They documented that a significant increase in neonatal hemoglobin, hematocrit, and red blood cells which were achieved by DCC in a full term newborn suggesting effective placental transfusion. Increasing the hemoglobin, hematocrit, and red blood cells are considered important benefits of DCC for neonates especially in low and middle income countries where irondeficiency anemia is more prevalent. [29] Iron is important for central nervous system function and development, and plays a main role in assisting the myelination of the cells in the brain. Iron deficiency is associated with several cognitive deficits such as impaired motor development and altered affective responding. [47] Another researcher proposed to change hospital practice from ECC to DCC in the Peruvian Amazon with a training program and hospital directive which may help to combat infant anemia in low resource settings and to decrease the higher incidence of children anemia [48].

On the other hand Katheria et al. and Jahazi et al. $[49,50]$ had reported different results. Where is the former had conducted a randomized clinical trial entitled "neonatal resuscitation with an intact cord". They showed no significant difference in the primary outcome of peak hematocrit in the first 24 hours of life between early and delayed cord clamping groups. The latter had studied "the effect of early and late umbilical cord clamping on neonatal hematocrit". They found that neonatal hematocrit level at $2 \mathrm{~h}$ and $18 \mathrm{~h}$ of life did not significantly differ between both groups. This discrepancy between the present study findings and the findings of contradictory studies might be attributed to the difference in the time of evaluation for hematocrit. Where, in the current study, all hematological parameters was done at $6^{\text {th }}$ day of newborns' life while in the contradictory studies the investigations were done within 24 hours of newborns' life.

There is a widespread belief that placental transfusion through DCC or umbilical cord milking increases the newborn's risk for jaundice. This has hindered the adoption of placental transfusion techniques in clinical practice [51]. The finding of the current study indicated that, the mean total bilirubin level was significantly higher, but still within the low intermediate risk in the DCC group than in ECC group, $13.89 \pm 2.22 \mathrm{mg} / \mathrm{dl}$ versus $12.66 \pm 3.12$ $\mathrm{mg} / \mathrm{dl}$ respectively. Therefore, evidence that the practice of DCC is associated with severe hyperbilirubinemia is lacking. This finding is supported by Zahir et al. [52] in their study about "the pharmacological features of bilirubin" suggested that bilirubin levels that are raised but still within a normal range (accompanying with a physiological jaundice) may provide a unique protective antioxidant effect, especially for the developing brain. 
Furthermore, the recent evidence of Garabedian et al. [45] support that higher levels of bilirubin within normal limits may add neuroprotection to the newborns.

In addition, Eichenbaum-Pikser and Zasloff [53] who had studied "delayed clamping of the umbilical cord". Stated that DCC slightly increase rates of hyperbilirubinemia in the newborn. Moreover, two systematic reviews conducted by Rabe et al. and McDonald \& Middleton [12,30] showed that delayed cord clamping lead to increased risk of neonatal jaundice in a newborns due to high blood bilirubin content. Also, American College of Obstetricians and Gynecologists [54] which stated that, delayed cord clamping was associated with small increase in the incidence of jaundice require phototherapy in term infant undergoing this practice.

In contrast, at least two studies found to be in contrary to the current study findings. The first, El Sakka et al. [55] who had conducted their study in 84 infants of diabetic mothers to investigate "the effect of DCC on blood sugar and venous hematocrit levels in term infants of diabetic mothers”. They confirmed that there were no statistical significant differences between the studied groups (immediate cord clamping, 1 minute and 2 minutes delayed cord clamping groups) as regard bilirubin level and need for phototherapy. Second, Al-Tawil et al. [56] Who had conducted "a randomized controlled trial on DCC and iron status at 3-5 months in term neonates held at the level of maternal pelvis". They showed that serum bilirubin level didn't differ significantly between neonates experienced ECC or DCC. This discrepancy between the present study and the latter group studies might be attributed to the difference in the time of evaluation for bilirubin level where in the current study we conduct the bilirubin level at $6^{\text {th }}$ day of newborns' life while in the contradictory studies done at 24 hours and then at 3-5 months postnatally. In light of inconsistent evidence, consideration of bilirubin level and neonatal outcomes in further studies are necessary.

\section{Conclusion}

Based on the findings of this study, $\mathrm{H} 1$ is accepted and $\mathrm{H} 0$ and $\mathrm{H} 2$ are rejected. It can be concluded that DCC did not increase the risk of maternal $\mathrm{PPH}$, duration of third stage of labour or the need for manual removal of the placenta. Furthermore, it is significantly increased neonatal hemoglobin, hematocrit, and RBCs. In addition, the mean total bilirubin level was significantly higher in the DCC group, but still within a low intermediate risk (below $75^{\text {th }}$ percentile) which did not require massive intervention.

\section{Recommendation}

- Training program should be conducted by the hospitals training centers for obstetricians, midwives and nurse-practitioners to increase their awareness regarding DCC in order to achieve the mothers and newborns benefits.

- Institutionalization of DCC in all governmental hospitals through providing policies, procedures and guidelines regarding this practice. This could significantly improve the intra natal care for the neonates without harmful consequences to the mother.

- The curricula of nursing/midwifery education should involve DCC intervention and its benefits. This may help in providing positive altitude of the future health care providers toward DCC.

- Future researches should be conducted to:

- Evaluate the effect of deferred versus early umbilical cord clamping on neonatal outcomes and iron status at 6 months after birth.

- Determine the optimal timing required to provide extreme benefit of placental transfusion at normal birth compared to cesarean section.

- Determine the effect of DCC on total, direct, indirect bilirubin level at different neonatal ages.

\section{References}

[1] WHO. Technical Consultation on Postpartum and Postnatal Care. Department of making pregnancy safer. WHO/MPS/10.03. Geneva, October 18-20, 2006.

[2] Fathima, N., \&Ramana R.M.V. An evaluation of the practice of active management of third stage of labour in a teaching hospital. Int J Reprod Contracept Obstet Gynecol 2016; 5: 1705-8.

[3] Gülmezoglu, A.M., Lumbiganon, P., Landoulsi, S., Widmer, M., Abdel-Aleem, H., Festin, M., Carroli, G., Qureshi, Z., Souza, J.P., Bergel, E., et al. Active management of the third stage of labour with and without controlled cord traction: a randomized, controlled, no inferiority trial. Lancet, 2012 May 5; 379(9827): 1721-1727.

[4] Westhoff, G., Cotter, A.M., \&Tolosa, J.E. Prophylactic oxytocin for the third stage of labour to prevent postpartum hemorrhage. Cochrane Database Syst Rev. 2013 Oct 30; (10): CD001808.

[5] WHO. Active Management Of The Third Stage Of Labour New WHO Recommendations Help to Focus Implementation. Maternal and child health integrated program. 2012; 14(18).

[6] Royal college of obstetrics and gynecologists. Clamping of the Umbilical Cord and Placental Transfusion. Scientific Impact Paper No. 14February 2015.

[7] Blouin, B., Penny, M.E., Casapia, M., Aguilar, E., Silva, H., Joseph, S.A., Creed-Kanashiro, H.M., Maheu-Giroux, M., Gyorkos, T.W. Effect of a two-component intervention to change hospital practice from early to delayedumbilical cord clamping in the Peruvian Amazon. Rev Panam Salud Publica. 2011 May: 29(5): 322-8.

[8] Kluckow, M., \& Hooper, S.B. Using physiology to guide time to cord clamping. Seminars in Fetal \& Neonatal Medicine 2015 Aug; 20(4): 225-231.

[9] McDonald, S.J., \& Middleton, P., Effect of timing of umbilical cord clamping of term infants on maternal and neonatal outcomes. Cochrane Database of Systematic Reviews, 2008 Apr 16; (2): CD004074.

[10] International Confederation of Midwives, International Federation of Gynecology and Obstetrics (FIGO). Joint Statement: Management of the Third Stage of Labour to Prevent Post-partum Haemorrhage. [The Hague, The Netherlands]: ICM; 2003 http://www.internationalmidwives.org/assets/uploads/documents/F IGO/PPH\%20Joint\%20Statement.pdf.

[11] Ersdal, H.L., Linde, J., Mduma, E., Auestad, B., \& Perlman, J. Neonatal outcome fol-lowing cord clamping after onset of spontaneous respiration. Pediatrics, 2014 Aug; 134(2): 265-72.

[12] Rabe, H., Diaz-Rossello, J.L., Duley, L., \& Dowswell, T. Effect of timing of umbilical cord clamping and other strategies to influence placental transfsion at preterm birth on maternal and infant outcomes. Cochrane Database Syst Rev. 2012 Aug 15; (8): CD003248.

[13] Baenziger, O., Stolkin, F., Keel, M., von Siebenthal, K., Fauchere, J.C., Das Kundu, S., Dietz, V., Bucher, H.U., \& Wolf, M. The influence of the timing of cord clamping on postnatal cerebral oxygenation in preterm neonates: a randomized, controlled trial. Pediatrics, 2007 Mar; 119(3): 455-459. 
[14] Jason, A. Meierhenry, Ryzhuk V, Maricel G. Miguelino, Lankford L, Jerry S. Powell, Farmer D, Wang A. Meierhenry, J.A., Ryzhuk, V., Miguelino, M.G., Lankford, L., Powell J.S., Farmer, D., \& Wang, A. Placenta as a Source of Stem Cells for Regenerative Medicine. CurrPathobiol Rep. 2015; 3(1):9-16.

[15] Kim, A.J., \& Warren, J.B. Optimal Timing of Umbilical Cord Clamping: Is the Debate Settled? Part 2 of 2: Evidence in Preterm and Term Infants, Alternatives, and Unanswered Questions. APP news journal. 2015; 16(5).

[16] Andersson, O., Hellström-Westas, L., Domellöf, M. Elective caesarean: does delay in cord clamping for $30 \mathrm{~s}$ ensure sufficient iron stores at 4 months of age? A historical cohort control study. BMJ Open, 2016 Nov 2; 6(11):e012995.

[17] Committee on Obstetric Practice, American College of Obstetricians and Gynecologists. Committee Opinion No. 543: Timing of umbilical cord clamping after birth. Obstet Gynecol, 2012 Dec; 120(6): 1522-1526.

[18] Al-Wassia, H, Shah, P.S. "Efficacy and safety of umbilical cord milking at birth: a systematic review and meta-analysis”. JAMA Pediatr, 2015 Jan; 169(1):18-25.

[19] Katheria, A., Blank, D., Rich, W., \& Finer, N. Umbilical cord milking improves transition in premature infants at birth. PLoS One. 2014; 9(4):e94085.

[20] Winter, C., Macfarlane, A., Deneux-Tharaux, C., Zhang, W.H., Alexander, S., Brocklehurst, P. et al. Variations in policies for management of the third stage of labour and the immediate management of postpartum haemorrhage in Europe. BJOG 2007 Jul; 114(7): 845-54.

[21] Hassan, F.M., El-Gendy, F.M., Badra, H.S., Kamal Eldin, S.M., \&Elsayyad, D.M. Evaluation of iron-deficiency anemia in infancy. Menoufia Med J 2016; 29: 269-274.

[22] American academy of pediatrics. Management of Hyperbilirubinemia in the Newborn Infant 35 or More Weeks of Gestation. American journal of pediatrics; 2004:114(1): 297-316.

[23] Garofalo, M., \&Abenhaim, H.A. Early versus delayed cord clamping in term and preterm births: a review. J Obstet Gynaecol Can. 2012 Jun; 34(6): 525-31.

[24] Mercer, J.S., Erickson-Owens, D.A., Collins, J., Barcelos, M.O., Parker, A.B., \& Padbury, J.F. Effects of delayed cord clamping on residual placental blood volume, hemoglobin and bilirubin levels in term infants: a randomized controlled trial. JPerinatol. 2017 Mar; 37(3): 260-264.

[25] Backes, C.H., Huang, H., Cua, C.L., Garg, V., Smith, C.V., Yin, H., Galantowicz, M., Bauer, J.A., \& Hoffman, T.M. Early versus delayed umbilical cord clamping in infants with congenital heart disease: a pilot, randomized, controlled trial. J Perinatol. 2015 Oct;35(10): 826-831.

[26] Chidre Y.V., \&Chirumamilla, v. Impact of early versus delayed umbilical cord clamping on post-partum blood loss: a randomized controlled trial. Int J Reprod Contracept Obstet Gynecol. 2015 Aug;4(4): 1103-1108.

[27] Andersson, O., Hellström-Westas, L., Andersson, D., Clausen, J., \&Domellöf, M. Effects of delayed compared with early umbilical cord clamping on maternal postpartum hemorrhage and cord blood gas sampling: a randomized trial. Acta Obstet Gynecol Scand. 2013 May; 92(5):567-74

[28] Dauda, s., \& Muhammad, C. A. Synthesis of Literature on the Timing, Clamping, and Clamping of Umbilical Cord in Newborn Babies. International Journal of Nursing and Health Science. 2016; 3(5):37-42.

[29] McDonald, S. J., Middleton, P., Dowswell, T \& Morris, P. S. effect of timing of umbilical cord clamping of term infants on maternal and neonatal outcomes (Review)", Evidence-based child health: A Cochrane Review Journal, 2014; 9(2):303-397.

[30] McDonald, S. J \& Middleton, P. effect of timing of umbilical cord clamping of term infants on maternal and neonatal outcomes (Review), Cochrane database systemic review, 2009; issue 1, pp.1-92.

[31] Prendiville, W.J., Harding, J.E., Elbourne, D.R., \& Stirrat, G.M. The Bristol third stage trial: active versus physiological management of third stage of labour.BMJ. 1988 Nov 19; 297(6659): 1295-300.

[32] Andersson, O. Effects of Delayed versus ECC on Healthy Term Infants. Acta Universitatis Upsaliensis. Digital Comprehensive Summaries of Uppsala Dissertations from the Faculty of Medicine, 2013; 893. 66 pp.
[33] McDonald S.J., Middleton, P., Dowswell, T., \&Morris, P.S. Effect of timing of umbilical cord clamping of term infants on maternal and neonatal outcomes. Cochrane Database Syst Rev. 2013 Jul 11; (7): CD004074.

[34] Abalos, E. Effect of timing of umbilical cord clamping of term infants on maternal and neonatal outcomes: RHL commentary. The WHO Reproductive Health Library; Geneva: 2009; World Health Organization.

[35] WHO. Guideline: Delayed umbilical cord clamping for improved maternal and infant health and nutrition outcomes. Geneva, World Health Organization; 2014

(http://www.who.int/nutrition/publications/guidelines/cord_clampi ng/en/).

[36] Airey, R.J., Farrar, D., \&Duley, L. Alternative positions for the baby at birth before clamping the umbilical cord. Cochrane Database Syst Rev, 2010; 6(10): CD007555.

[37] Ahmad, E.R., Aly, S.A., \&Zahran, K.M. Effect of Early Versus Late Umbilical Cord Clamping of Term Infants on Maternal and Neonatal Outcomes. J Am Sci 2012; 8(9):745-752.

[38] Jelin, A.C., Zlatnik, M.G., Kuppermann, M., Gregorich, S.E., Nakagawa, S., \&Clyman, R. Clamp late and maintain perfusion policy: delayed cord clamping in preterm infants. J Matern Fetal Neonatal Med.2016; 29(11): 1705-9.

[39] Fawzy, A.A., Moustafa, A.A., El-Kassar, Y.S., Swelem, M.S., El-Agwany, A.S., \&Diab, D. A. Early versus delayed cord clamping of term births in Shatby Maternity University Hospital, Progresos de Obstetricia y Ginecología, November 2015, 58(9): 389-392.

[40] Kugelman, A., Borenstein-Levin, L., Riskin, A., Chistyakov, I., Ohel, G., Gonen, R., \& Bader, D. Immediate versus delayed umbilical cord clamping in premature neonates born \&lt; 35 weeks: a prospective, randomized, controlled study. Am J Perinatol. 2007 May; 24(5): 307-315.

[41] Katheria, A.C., Lakshminrusimha, S., Rabe, H., McAdams, R., \& Mercer, J.S. Placental transfusion: a review. J Perinatol. 2017 Feb; 37(2): 105-111.

[42] Lakshminrusimha, S., \&Neurs, K.V. Better timing for cord clamping is after onset of lung aeration. Paed Res 2015; 77:615-7.

[43] Strauss, R.G., Mock, D.M., Johnson, K.J., Cress, G.A., Burmeister, L.F., Zimmerman, M.B,, Bell, E.F., \&Rijhsinghani, A. A randomized clinical trial comparing immediate versus delayed clamping of the umbilical cord in preterm infants: short-term clinical and laboratory endpoints. Transfusion. 2008 Apr; 48(4): 658-65.

[44] Gamal, A.M., Zein El Dein, N.A., \& Omar, T.K. Clamping Time and Its Effect on Mothers and Their Full Term Newborns, IOSR Journal of Nursing and Health Science, 2015; 4( 2):52-60.

[45] Garabedian, C., Rakza, T., Drumez, E., Poleszczuk, M., Ghesquiere, L., Wibaut, B., Depoortere, M.H., Vaast, P., Storme, L., \& Houfflin-Debarge, V. Benefits of Delayed Cord Clamping in Red Blood Cell Alloimmunization. Pediatrics. 2016 Mar; 137(3): e20153236.

[46] Raju, T.N. Timing of umbilical cord clamping after birth for optimizing placental transfusion. Curr Opin Pediatr. 2013 Apr; 25(2): 180-7.

[47] Houston, J., Dillon, L., Duvall, A. and McGuire, M. Bridging the Gap between Evidence and Practice: A Systematic ReviewWhen Is the Best Time to Clamp the Infant's Umbilical Cord in Term Low-Risk Women?, Open Journal of Nursing, 2014; 4, 730736.

[48] Blouin, B., Penny, M., Casapia, M., Eder, A., Hermann, S., Joseph, S., Creed-Kanashiro, M., Maheu-Giroux, M. \&Gyorkos, T.W. Effect of a Two-Component Intervention to Change Hospital Practice from Early to Delayed Umbilical Cord Clamping in the Peruvian Amazon. Revista Panamericana de Salud Pública, 2011; 29, 322-328.

[49] Katheria, A., Poeltler, D., Durham, J., Steen, J., Rich, W., Arnell, K., Maldonado, M., Cousins, L., \& Finer, N. Neonatal Resuscitation with an Intact Cord: A Randomized Clinical Trial. JPediatr. 2016 Nov; 178: 75-80.

[50] Jahazi, A., Kordi, M., Mirbehbahani, N.B. \&Mazloom, S.R. The Effect of Early and Late Umbilical CordClamping on Neonatal Hematocrit. Journal of Perinatology, 2008; 28, 523-525.

[51] Jelin, A.C., Kuppermann, M., Erickson, K., Clyman, R., Schulkin, J. Obstetricians' attitudes and beliefs regarding umbilical cord clamping. J Matern Fetal Neonatal Med. 2014 Sep; 27(14): 1457-61. 
[52] Zahir, F., Rabbani, G., Khan, R.H., Rizvi, S.J., Jamal, M.S., \&Abuzenadah, A.M. The pharmacological features of bilirubin: the question of the century. Cell MolBiol Lett. 2015; 20(3): 418-447.

[53] Eichenbaum-Pikser, G., \&Zasloff, J.S. Delayed clamping of the umbilical cord: a review with implications for practice. J Midwifery Womens Health. 2009 Jul-Aug; 54(4): 321-326.

[54] American College of Obstetricians and Gynecologists. Committee Opinion No. 543: Timing of umbilical cord clamping after birth. Obstet Gynecol. 2012; 120(6): 1522-1526.
[55] El Sakka, A., El chimi, M.S., Ibrahium, R., Farid, Y.A., Salama, M., \& Tawfik, H. Effect of Delayed Umbilical Cord Clamping on Blood Sugar and Venous Hematocrit levels in Term Infants of Diabetic Mothers. Journal of American Science, 2012; 8(12): 574-578.

[56] Al-Tawil, M.M., Abdel-Aal, M.R., \&Kaddah, M.A. A randomized controlled trial on delayed cord clamping and iron status at 3-5 months in term neonates held at the level of maternal pelvis, Journal of Neonatal-Perinatal Medicine, 2012; 5(4): 319-326. 